\title{
RFID-BASED OCCUPANCY DETECTION SOLUTION FOR OPTIMIZING HVAC ENERGY CONSUMPTION
}

\author{
Shuai Li*, Nan Li, Burcin Becerik-Gerber, and Gulben Calis \\ Sonny Astani Department of Civil and Environmental Engineering, University of Southern California, \\ Los Angeles, USA \\ *Corresponding author (shuail@usc.edu)
}

\begin{abstract}
Current building climate control systems often rely on predetermined maximum occupancy numbers coupled with temperature sensor data to regulate heating, ventilation, and air conditioning (HVAC). However, rooms and zones in a building are not always fully occupied. Real-time occupancy information can potentially be used to reduce energy consumption. The paper proposes an RFID-based occupancy detection solution to address the need for real-time in-building occupancy information. The proposed solution can track real-time location of tagged occupants, and report the occupancy at the zone level. A prototype was built and tested in a campus-dining hall with three zones. Occupants who were waiting in a queue, walking, or sitting were equipped with active RFID tags. The results demonstrated that the location of occupants could be estimated and $71 \%$ of the occupants could be detected at the right predefined zone. Based on the findings, detailed and operable strategies for optimizing HVAC-related building energy consumption by using occupancy information are proposed.
\end{abstract}

Keywords: Occupancy Detection, RFID, Building Energy Consumption, Optimization, HVAC

\section{INTRODUCTION}

Few topics are more relevant in current times than energy management. Global climate change, a growing population, decreasing availability of fossil fuels, increasing environmental and economic concerns regarding energy use are driving forces towards more sustainable ways of responding to the energy needs. In the U.S., 48\% of energy consumption is from buildings, $35 \%$ of which is consumed by heating, ventilation, and air conditioning (HVAC) systems [1]; therefore, they are prime targets for energy optimization. Previous research suggests that improvements in operation and management of HVAC systems can save up to $50 \%$ of building's energy consumption [2,3]. Occupancy information is an important variable to determine the heating and cooling loads, and it affects how HVAC systems are adjusted to satisfy various occupant demands. Ideally, building operations automatically would respond to environmental uncertainties and dynamic occupancy load factors [4]. However, current facility management practices usually rely on gross generalizations to operate HVAC systems, such as operating for the peak occupancy load as opposed to the optimal, leading to more energy consumption than needed. A prime example is occupant congregations within a building space requiring optimization of space temperature control due to thermal heat gains. The availability and integration of occupancy information in operations of HVAC systems bear significant promise in reducing heating and cooling energy consumption.

Due to potential energy savings, the topic of occupancy driven HVAC operations has attracted considerable attention in academic research. To lay the basis of occupancy driven HVAC operations, different solutions were proposed to detect the existence of occupants [2-5]. With the occupancy information, timely adjustments to HVAC systems such as redirecting air flows and reducing system running time are made possible in response to either real-time occupancy loads, or predicted loads based on historical data $[3,6]$. Energy savings were estimated 
through simulations, which varied between $10 \%$ and $60 \%$ $[2,7]$.

This study proposes an occupancy detection solution to be integrated with HVAC operations, and evaluates the proposed solution's technological feasibility by testing it in a large open space. The rest of the paper is organized as follows: sections 2 review occupancy detection solutions for optimizing HVAC energy consumption; and section 3 identifies research challenges and objectives; sections 4 and 5 describe the research approach and findings for the proposed RFID-based occupancy detection solution; section 6 outlines the framework to implement occupancy information in optimizing the energy efficiency of HVAC systems; and section 7 concludes the paper.

\section{LITERATURE REVIEW}

Previous research investigated the feasibility and value of occupancy detection and implementation of occupancy driven HVAC operations. Warren and Harper [2] proposed that $\mathrm{CO}_{2}$ concentration could be sensed and monitored as an indication of high-level occupancy. Their research proposed to maintain a certain level of $\mathrm{CO}_{2}$ concentration in a room by adjusting the airflow volume, and reported a saving of 53.3\% in heating energy through simulation. Lee et al. [5] provided an occupancy detection solution that uses RFID sensors, but the system was coarse-grained and could only detect occupants that passed doors or sat at tables. Agarwal et al. [8] used passive infrared sensors to detect occupancy in each room, and proposed to maintain the temperature of a room at a comfortable level only when an occupant was detected in the room. Tachwali et al. [3] addressed the second limitation by quantizing the cooling air flow volume into three levels, and determined the volume based on occupancy in each room. Simulations reported an energy saving of up to $50 \%$, which, however, was subject to external weather conditions. Varick et al. [7] used a digital camera based occupancy detection solution to count occupants, which provided an accuracy of $80 \%$ in occupancy detection. This occupancy detection system suffered from high costs and privacy issues. Occupancy prediction based on logged occupancy information was also examined [9]. The research simulated to start conditioning a room to a comfortable temperature defined by American Society of Heating, Refrigerating and Airconditioning Engineers (ASHRAE) standards only when the room was predicted to be occupied for 10 minutes or longer. The research reported a saving of $20 \%$ in HVAC energy consumption. However, the occupant comfort was reduced, as the system tended to anticipate very low occupancy in some areas and provided an insufficient service.

\section{RESEARCH MOTIVATION AND OBJECTIVES}

The majority of the occupancy detection solutions in previous research were not intended for energy optimization. For those occupancy detection solutions aimed at occupancy driven HVAC operations, few were fine-grained and validated in real-life scenarios. Previous occupancy driven operation strategies were high level, proposing to regulate the airflow volume and HVAC system running time without specifying how these parameters were actually regulated. Moreover, previous research assumed that the energy savings were proportional to the reduction of airflow volume and running time is problematic, and therefore estimated the potential energy savings based on the reduction in airflow volume and running time.

Consequently, the first goal of this study is to propose an occupancy detection solution that can support occupancy driven HVAC operations by tracking multiple stationary and mobile targets simultaneously, and reporting occupancy loads for each thermal zone in real time. The second goal of this study is to examine current HVAC work procedures, identify and quantify major energy consumers, and propose detailed and operable strategies to realize occupancy driven HVAC operations and achieve energy savings.

\section{RESEARCH APPROACH}

\subsection{Occupancy detection algorithm}

This research uses a proximity based algorithm. It relies on received signal strength indication (RSSI) values of different tags, an indicator that is used to measure the strength of radio waves received by an antenna. The 
algorithm includes the following components: reference tags, tracking tags, and virtual tags. Reference tags are deployed in the sensing area as reference points. Virtual tags operate in the same way as reference tags except for that they are imaginary tags with estimated RSSI readings instead of actual measurement. Targets are located using locations of reference tags and virtual tags nearest to them. More details of the algorithm can be found in [10,11].

\subsection{Test description}

Tests were carried out in a campus dining hall at the University of Southern California. The test bed covered an area of $12.5 \mathrm{~m}$ wide, $24.3 \mathrm{~m}$ long, $3.5 \mathrm{~m}$ high, and hosted three food counters. The authors divided the test bed into three zones as shown in Figures 1 and 2. The rationale behind the space division is that each zone had different functions and are semi-separated by $1 \mathrm{~m}$ high partitions. Moreover, customization of isolated environments in an open space for localized climate control is proven to be possible [12], which provides more flexibility in space division so that it can be consistent with actual space geometry and usage. Zones 1 and 2 cover two individual food counters, where occupants stand in line for purchasing food and sit for having their meals. Zone 3 covers the area where occupants wait in line for purchasing their coffee. The test bed area is an open space with no walls or columns.
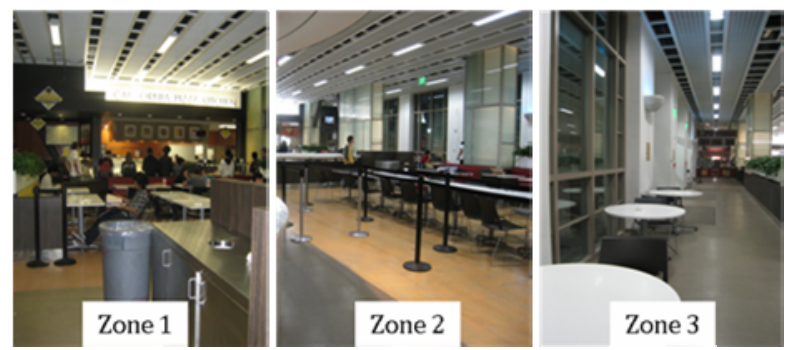

Figure 1: Photos of three zones

A total of 16 reference tags, 12 target tags (two types: 9 stationary tags and 3 mobile tags), 4 antennae and 2 readers were deployed. Three different scenarios for occupant activities were tested. Three occupants kept walking as they were choosing where to sit. Five occupants waited in line to get their food near the food counters. Four occupants were seated in the sitting area. Each mobile occupant moved to 5 different locations and the stationary occupants remained at the same locations. Figure 2 illustrates the locations of twelve occupants.

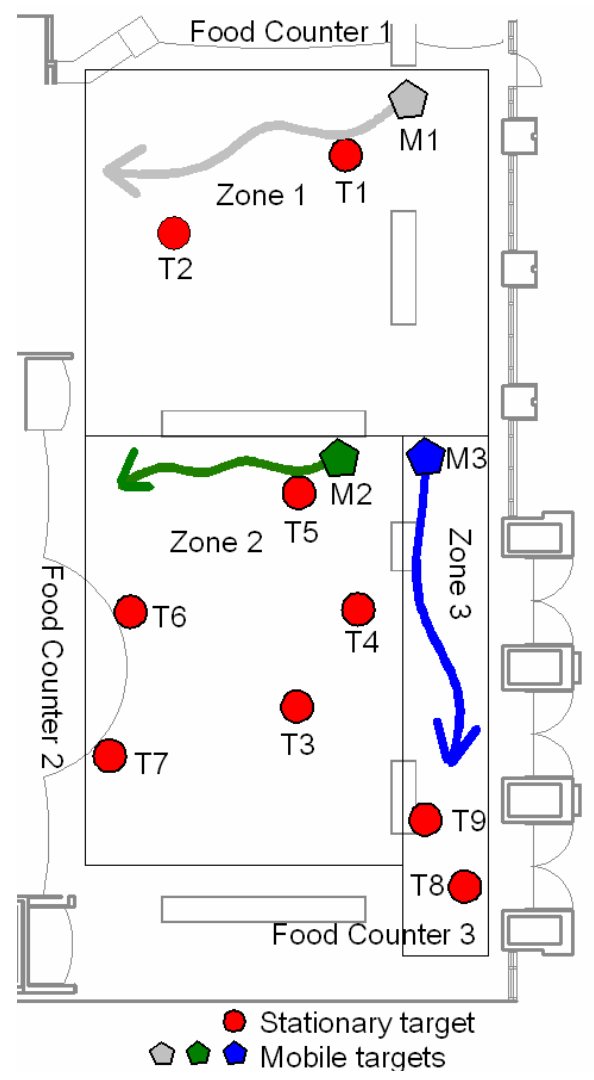

Figure 2: Test bed layout

\section{FINDINGS}

\subsection{Occupancy detection rate for each occupant type}

To evaluate the performance of RFID-based occupancy detection solution proposed in this research, the actual locations of all tagged occupants are compared with their estimated locations. Occupancy detection rate is defined as the percentage of both stationary and mobile occupants that were accurately estimated to be in the zones where they were actually located.

About $67 \%$ of all stationary occupants in all zones were accurately located. All stationary targets in Zone 1 and Zone 3 were accurately located in their zones, while the detection rate in Zone 2 was only 40\%. Target tag 6 was inaccurately located in Zone 1 and target tags 4 and 7 were inaccurately located in Zone 3. One explanation for the low accuracy in Zone 2 is that there were more occupants in 
this area compared to the other two associated with a more dynamic environment which could have caused a stronger interference of the radio wave emitted by multiple active RFID tags. Moreover, there were more students in zone 2 since food counter 2 is very popular which generated a higher environmental noise to decrease the detection accuracy. [13] The surrounding disturbance from students' movement could lead to significant changes in RSSI values which will result in unexpected lower detection rate.

As for the mobile occupants, two out of the three mobile occupants were accurately located in their zones throughout the test, and the overall accuracy detection rate for the mobile occupants was $66.7 \%$. The mobile occupants in zone 1 and 2 were accurately located throughout the tests with $100 \%$ detection rate. The detection rate for the mobile tag in Zone 3 was only 20\%, which meant that only one out of five locations was accurately estimated. The rest of the four locations were inaccurately estimated to be either in Zone 2 or Zone 1. Compared with the stationary occupants, the mobile occupants may fluctuate between low and high points of radio wave phases with a large spread which will generate a larger deviation in the detection rate [14].

\subsection{Occupancy detection rate for each zone}

The overall occupancy detection rate for all three zones was $71 \%$. The occupancy detection rate for each zone is shown in Table 1.

Table 1: The occupancy detection rate for three zones

\begin{tabular}{ccccc}
\hline & $\begin{array}{c}\text { \# of } \\
\text { stationary } \\
\text { occupants }\end{array}$ & $\begin{array}{c}\text { \# of } \\
\text { mobile } \\
\text { occupants }\end{array}$ & $\begin{array}{c}\text { \# of } \\
\text { estimated } \\
\text { locations }\end{array}$ & $\begin{array}{c}\text { Average } \\
\text { accuracy } \\
\text { rate }\end{array}$ \\
\hline Zone 1 & 2 & 1 & 7 & $100 \%$ \\
Zone 2 & 5 & 1 & 10 & $70 \%$ \\
Zone 3 & 2 & 1 & 7 & $44 \%$ \\
\hline
\end{tabular}

The highest occupancy detection rate was achieved in zone

1, where all occupants were accurately located. As the smallest zone on the boundary of sensing area, Zone 3 generated the worst occupancy detection rate. The estimated mobile occupant route and stationary occupant locations in zone 1 were shifted towards zone 2 . If the occupants had been walking around or seated near the boundary between zone 1 and zone 2, they might well be estimated inaccurately in zone 2.

\subsection{Occupancy detection rate for each occupant location type}

Based on their locations, occupants can be divided into two categories: boundary occupants that are next to the boundary of the sensing area, and central occupants that are located at the center of the sensing area. Table 2 presents detection rates of occupants at different locations.

Occupancy detection rate can be affected by where the occupants are located, near the boundary or at the center of the sensing area. The boundary occupants were less accurately located than central occupants with decrease of $29 \%$ in occupancy detection rate. The worse results were mainly because those boundary occupants were not in the complete coverage of the nearby reference tags.

Table 2: Occupancy detection rate for occupants at different locations

\begin{tabular}{cccc}
\hline & $\begin{array}{c}\text { Occupant } \\
\text { IDs }\end{array}$ & $\begin{array}{c}\text { \# of estimated } \\
\text { locations }\end{array}$ & $\begin{array}{c}\text { Average } \\
\text { accuracy rate }\end{array}$ \\
\hline \multirow{3}{*}{ Boundary } & $\begin{array}{c}\text { T1 T2, T6, } \\
\text { T7. T8, T9 }\end{array}$ & 16 & \\
Occupants & $\begin{array}{c}\text { M1, M3 } \\
\text { Central }\end{array}$ & & \\
\hline Occupants & T5, T4, M2 & 8 & $87.5 \%$ \\
\hline
\end{tabular}

\section{ENERGY SAVING IMPLICATIONS}

The test results indicate that the proposed occupancy detection solution can locate the majority of occupants at the zone level in real time. To identify and quantify potential sources of energy savings, the procedure of a typical HVAC system is examined. Chillers and heaters that serve one or multiple buildings generate chilled or heated water. Air handler units (AHUs) that serve the whole or part of a building take in outdoor air, mix it with 
air flows that return from all thermal zones, and cool or heat the mixed air to a set point with chilled or heated water. The conditioned air is then distributed by fans to all thermal zones. The demand for the volume of conditioned air of a thermal zone is determined by the difference between the zone's actual temperature and the set point, and is regulated by the VAV box that serves this zone.

There are two major energy consumers in this procedure: the production and distribution of chilled and heated water at the building level, and the distribution of conditioned air at the thermal zone level. To quantify the energy consumption, a simple model is established as follows:

Suppose $V_{b z}$ is the amount of outdoor air the AHU takes in with temperature $T_{o s a}$, and $V_{s a}$ is the amount of air distributed to all thermal zones, $T_{z}$ is the temperature of mixed returning air from all thermal zones. The temperature of the mixed air is:

$$
T_{m a}=\left(V_{b z} / V_{s a}\right) T_{o s a}+\left(1-\left(V_{b z} / V_{s a}\right)\right) T_{z}
$$

The energy needed to generate chilled or heated water to condition the mixed air is:

$$
Q_{c w}=0.21 \times 1.1 \times\left(T_{m a}-T_{s a}\right) \times V_{s a}
$$

where $T_{s a}$ is the average indoor temperature.

The energy consumption for distributing the air flow is;

$$
Q_{\text {fan }}=1.25 \times 3.412 \times V_{\text {sa }}
$$

The total energy consumption by the HVAC system is:

$$
Q_{z}=Q_{c w}+Q_{f a n}
$$

Accordingly, if some thermal zones are detected to have no or low occupancy and the heating and cooling loads are therefore lower than the scheduled peak loads, the following strategies can be taken into account to adjust the HVAC operations to reduce the energy consumption:

1. Adjusting in-take air volume $V_{b z}$. Reducing $V_{b z}$ will lead to reduction in the temperature of mixed air $T_{m a}$ and hence the chilled water production and distribution energy consumption $Q_{c w}$. However, to ensure the indoor air quality, the in-take air is subject to a minimum volume per ASHARE standards;
2. Adjusting supply air temperature $T_{\mathrm{s} a}$. Increasing $T_{\mathrm{s} a}$ will result in reduction in the chilled water production and distribution energy consumption $Q_{c w}$. However, given a certain cooling or heating load, this strategy requires an increase in supply air volume $V_{s a}$;

3. Adjusting the supply air volume $V_{s a}$. Reducing $V_{s a}$ will result in reduction in both chilled water production energy consumption $Q_{c w}$ and supply air distribution energy consumption $Q_{\text {fan }}$. However, given a certain cooling or heating load, this strategy requires a decrease in supply air temperature $T_{s a}$.

The limitations and tradeoffs in implementing each of these strategies are discussed. An integral strategy requires the input of all parameter values, which lays the basis of quantifying the potential energy savings through theoretical calculations or simulations.

\section{CONCLUSION}

The paper proposed an RFID-based occupancy detection solution to measure the real-time in-building occupancy information. The HVAC system control routine can be potentially directed with the occupancy driven strategy to optimize the energy consumption. Therefore, the energy consumption can be reduced in the areas where there are few occupants. To test the feasibility of occupancy detection to support optimization of HVAC energy efficiency, an RFID-based occupancy detection solution was developed and deployed in a campus-dining hall.

The proposed RFID-based occupancy detection solution demonstrated an overall detection rate of $71 \%$. However, the occupancy detection rate varied with different zones, occupant types and locations of occupants in the sensing area. Stationary occupants located in the center of the sensing area were estimated with a higher accuracy compared with mobile occupants and boundary occupants. Overall, the proposed RFID based occupancy detection solution proved to be effective to detect most occupants and has the potential to provide occupancy driven 
strategies for the HVAC operations. Nevertheless, additional efforts should be devoted to further improvement on current occupancy detection rate. Possible solutions include increasing the density of sensors, incorporating algorithm calibration, reducing environmental effects and so on. With the availability of zone level occupancy information, major energy consumers in current HVAC work procedure were recognized, and a model was established to quantify the energy consumption. Potential energy savings were identified, and three strategies were proposed accordingly, with their values, limitations, and tradeoffs discussed. Once implemented, these strategies are expected to utilize the occupancy information to save HVAC related energy consumption.

\section{ACKNOWLEDGEMENTS}

We greatly appreciate the support of Lygnsoe Systems, Inc, who funded and supported this research. Any opinion, findings, conclusions expressed in this paper are these of the authors and do not necessarily reflect the views of Lygnsoe Systems, Inc.

\section{REFERENCES}

[1] US Department of Energy, Building Energy Data Book, 2011.

[2] Warren, B.F. and Harper. N.C., "Demand controlled ventilation by room $\mathrm{CO} 2$ concentration. A comparison of simulated energy savings in an auditorium space", Energy Build, Vol. 17, pp. 87-96, 1991.

[3] Tachwali Y., Refai H., Fagan J.E., "Minimizing HVAC energy consumption using a wireless sensor network", IEEE, Piscataway, pp. 439-44, 2007.

[4] Qin J., Li B., Salsbury T., "Identification and control for optimizing building energy demand", 2009.

[5] Lee H., Jae S.C., Elmasri R., "A conflict resolution architecture for the comfort of occupants in intelligent office", IET, pp. 3-4, 2008.
[6] Newsham G.R., Birt B.J., "Building-level occupancy data to improve ARIMA-based electricity use forecasts", Association for Computing Machinery, pp. 13-18, 2010.

[7] Erickson V.L., Lin Y., Kamthe A., Brahme R., A, Surana A.E. et al., "Energy efficient building environment control strategies using real-time occupancy measurements", Association for Computing Machinery, pp. 19-24, 2009.

[8] Agarwal Y., Balaji B., Gupta R, et al., "Occupancydriven energy management for smart building automation", Association for Computing Machinery, pp. 1-6, 2010.

[9] Erickson V.L., Cerpa A.E., "Occupancy based demand response HVAC control strategy", Association for Computing Machinery, pp. 7-12, 2010.

[10] Li N., Li S., Becerik-Gerber B., et al., "Design and Evaluation of Algorithm and Deployment Parameters for an RFID-Based Indoor Location Sensing Solution", Proceedings of 2011 ASCE International Workshop on Computing in Civil Engineering, 2011.

[11] Li N., Li S., Becerik-Gerber B., et al., "Deployment Strategies and Performance Evaluation of a Virtual-TagEnabled Indoor Location Sensing Approach", J.Comp.in Civ.Engrg, under review, 2011.

[12] Lo L.J., Novoselac A., "Localized air-conditioning with occupancy control in an open office", Energy Build, Vol. 42, pp. 1120-1128, 2010.

[13] Li S., Li N., Calis G., et al., "Effects of Environmental Factors on the Accuracy of RFID-Based Indoor Location Sensing Systems", Journal of Advanced Engineering Informatics, under review, 2011.

[14] Zhao Y., Liu Y., Ni L.M., "VIRE: active RFID-based localization using virtual reference elimination", IEEE, Piscataway, 2007. 